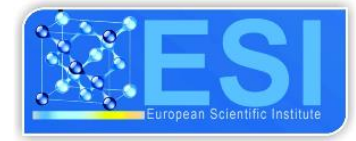

10 years ESJ

Special edition

\section{Samantha Nanayakkara}

University of Colombo, Sri Lanka

Submitted: 31 August 2020

Accepted: 30 September 2020

Published: 31 December 2020

Corresponding author:

Samantha Nanayakkara

DOI: $10.19044 /$ esj.2020.v16n39p95

cc) Copyright 2020 Nanayakkara S.

Distributed under Creative Commons

BY-NC-ND 4.0 OPEN ACCESS

\section{Educating youth through sport: Understanding Pierre de Coubertin's legacy today}

\begin{abstract}
More than a century ago now, the founder of contemporary Olympics, Pierre de Coubertin emphasized the importance of educating youth through sport to create a better and peaceful world. This study aimed to find answer to the posed question, whether Coubertin's concept can indeed apply to the youth generation at present. Thus, this study examined the potentiality of Olympism as a powerful vehicle for teaching youths the life skills for conflict resolution and inculcating positive knowledge, attitudes, values and morals through the medium of physical education and sport. This study proposed a framework for developing a conflict resolution curriculum model through Olympism and tested it within a strongly ethnically polarized society in Sri Lanka. Introducing the concepts of Olympic values to the secondary school curriculum showed real promise in helping youth to acquire fundamental social skills and ethical values. It has contributed to the academic knowledge of the use of Olympism and has demonstrated how it might be used to strengthen the sport and education nexus and to improve young students' conflict resolution competencies.
\end{abstract}

Keywords: multiculturalism, Olympism, conflict resolution, socio-cultural values

\title{
Introduction
}

Pierre de Coubertin conceived modern Olympism in 1894 (IOC, 2007). According to the fundamental principles of the Olympic Charter (IOC, 2010), it seems that Olympism is a concept which aims to promote peaceful societies through sport and attempts to achieve this goal through the education of young people. Andrecs (2007) and Kruger (2007) confirm this view emphasising that Coubertin's thoughts on promoting a peaceful world through 
contemporary Olympism were always associated with the enhancement of the next generation. The popular educational models of Coubertin's time maintained that the ethical powers of youth could be cultivated and developed through their personal experience with sport activity, namely through activating or encouraging the ethical level in their broader social behaviour (Alfermann \& Bussmann, 1988; Shields \& Bredemeier, 1995). Coubertin was interested in reawakening the gymnasium of antiquity as a modern cultural factory for the harmonious and holistic education of young people (Naul, 2008). According to Kidd (1996) Coubertin came to believe that a system of highly competitive sport could inspire and energize the youth of France and thereby rouse the country out of its lethargy.

Coubertin strongly supported the discipline of amateur athletes and believed that sport was the most prestigious phenomena for the revolution of the younger generation (Muller, 2004). Coubertin considered the Games as a special kind of initiation ceremony with which a new generation of humans was to be celebrated. Kruger (2007) emphasises that "Olympic sport and the Olympic Games stand as symbols for the fact that the future can be mastered with youthful courage, energy and the hope for success" (p. 23). Kruger (2007) also pointed out that Olympic athletes are concrete examples of the behaviour which is necessary for doing so. Coubertin argued that sporting competition between the world's youth was meant "to promote virtues such as striving towards personal bests, mutual respect, the ethos of amateurism and working together for a peaceful world" (Andrecs, 2007, p. 9). For Coubertin, it is not only the major element of strength and socialisation for the young, but also the incredible force which is to liberate individual forces and release, from within, all the locks of the academic citadel (Boulongne, 1994). Ren (1997) confirms this view emphasising that Coubertin's thoughts were always associated with combining concepts of physical strength, along with intellectual and artistic performances. These scholarly debates reveal Coubertin's vision of a peaceful world brought about by educating youth through sport.

\section{Problem statement}

There are, however, specific issues which need to be considered, and critical questions to be asked regarding Coubertin's vision for educating youth through sport in contemporary society. It is timely to inquire whether Coubertin's concept for educating youth through sport has been promoted as he intended. So the key questions seems to be What impact would Coubertin's vision of "a peaceful world educating youth through sport" have within hyperneoliberal contemporary societies? How could youths be educated through sport within a market-driven social and political context? How could youths' sport participation play a vital role in promoting democracy in contemporary 
society? Why may youth involvement in democracy vary in different situations? How can youth be educated about social justice to resolve their conflicts while involving themselves in sports?

Both critical and problem-solving approaches to conflict resolution can be developed through teaching and learning about equity and social justice. Cardozo (2009) argues that "there should be space for discussions on sensitive themes, such as the recognition of truth and reconciliation in such educational programmes" (p. 31). Physical education is a subject that students encounter from primary school onwards, and it is important to investigate its capacity for dealing with critical questions grounded in significant social issues. The question to be asked is how can the secondary school curriculum area, particularly sub areas like Olympism in physical education, contribute to teaching about conflict resolution?

Conflict resolution is a constructive approach to interpersonal and intergroup conflicts that helps people with opposing positions work together to arrive at mutually acceptable compromise solutions (Deutsch, 1973). Conflict resolution can be defined in abstract terms as behaviours aimed at resolving perceived incompatibilities (Boulding, 1963; Thomas, 1976). It is evident that conflict resolution practice in schools is important and that different conflict resolution models have impacted differently on conflict situations in various schooling contexts. Bordine \& Crawford (1996) emphasised that the school-based violence prevention programmes must be implemented prior to adolescence. They also point out that it is important to establish peacemaking behaviour programmes in early education and best to disseminate its values beyond the individual child. Stevahn, Johnson, Johnson and Schultz (2002) revealed that conflict resolution is positively linked to a student's academic achievement. In a similar study, Vazsonyi, Belliston and Flannery (2004) examined a school-based evaluation named 'Universal Violence Prevention Programme: Low, Medium, and High-Risk Children'. They examined the effectiveness of 'Peace Builders', a large-scale, universal violence prevention programme, on male and female youth identified as low, medium or high risk for future violence. This is supported by Brown, Roderick, Lantieri and Aber (2004) conducting a School Based social and emotional learning programme named the 'Resolving Conflict Creatively Program'. The study recruited over 350 teachers and 11000 children from 15 public elementary schools to explore the programme's impact on children's trajectories of social and emotional learning and academic achievement.

Another study by Heydenberk and Heydenberk (2005), titled 'Increasing Meta-cognitive Competence through Conflict Resolution' aimed to determine the effects of conflict resolution and related social skill development on student's meta-cognitive competencies. The research outcome highlights the importance of integrating conflict resolution and social 
skill training into curricula. Roberts, Yeomans and Ferro-Almeida (2007) conducted an evaluation of a project named 'WIN' (Working out Integrated Negotiations) which has shown decreased violence and improved conflict resolution skills in middle school students. The results suggest that the programme effectively decreased reported violence and increased students' ability to apply conflict resolution tools in hypothetical conflict situations. It also indicated that students learned to transform competitive situations into cooperative ones. Bilgin (2008) examined the impact of conflict resolution training on elementary school children, and concluded that students should be taught to cope with conflicts through constructive strategies, because low academic achievement, low self-esteem, stress and violence are the results of destructive conflict resolution.

Nevertheless many scholars have examined conflict resolution at schools, although it seems that there is no research that has specifically used Olympism education in school physical education to teach children conflict resolution skills. It is important to investigate whether the concept of Olympism has the capacity to promote an atmosphere of friendship and solidarity among ethnically and culturally diverse young students, which can be considered prerequisites for conflict resolution and peaceful living. Olympism is a social philosophy which emphasises the role of sport in world development, international understanding, peaceful co-existence, and social and moral education (Parry, 2003). It is the contention of this author that the 'concept of Olympism' presents many opportunities to mitigate ethnic antagonisms and bring about harmonious relationships among different ethnic and cultural communities by providing sporting opportunities. It is also important to explore whether the UNESCO's theme "live together" and Coubertin's idea of "building a peaceful and better world by educating youth through sport" can indeed apply to multicultural situations. Therefore, it is necessary to examine the potentiality of Olympism as a powerful vehicle for teaching youth the life skills of conflict resolution and the possibilities of acquiring positive attitudes, values and morals through the medium of physical education and sport.

The main purpose of this article is to delineate the findings of a study that investigated how Olympism education could strengthen competencies of conflict resolution, through delivering socio-cultural values education among young students in ethnically divided societies in Sri-Lanka. A secondary purpose of this article aimed to find answers to the question whether Coubertin's idea of "building a peaceful and better world by educating youth through sport" can indeed apply to multicultural situations in contemporary societies. 


\section{Method}

This study was carried out in six ethnically and culturally diverse (Singhalese, Tamil and Muslim) provincial secondary schools in the Western Province, Sri Lanka. There were 23 secondary schools that play basketball in the Western province, Ministry of Education and six schools were randomly selected from the list of secondary schools that play basketball in the Western Province, Ministry of Education. There were 180 school basketball players consisting of 90 girls and 90 boys (aged 17-18 years) as research participants from above mentioned six schools, hereafter called School A,B,C,D, E \& F. Schools A \& C were Singhalese schools, schools, B \& D were Tamil schools, and E \& F were Muslim schools. There were 30 students 15 girls and 15 boys from each school and they were purposively selected as the research sample as they are representing their school basketball team. The rationale for the particular age group was that these students are in the transitional period for participating in the 'Youth Olympic Games'.

The key research question for this paper is can Sri Lankan young students apply their knowledge of Olympism to learn conflict resolution? In order to explore the lived experiences of young students, a qualitative research method was underpinned the study. Data for this study was obtained from indepth, focus group, semi-structured interviews which were conducted with 60 randomly selected students from above mentioned six schools (10 each; 5 girls $\& 5$ boys). The researcher was competent in both Sinhalese and Tamil languages and my role as a facilitator and researcher was clearly known by all the informants.

To assure the reliability and validity of data, all interviews were guided by a schedule of open-ended questions. The interviews were carried out in each sample school (A, B, C, D, E \& F) and lasted between 45-60 minutes. These interviews were recorded using a digital voice recorder (Panasonic; RRUSO50) and subsequently transcribed verbatim. Each transcript was double checked by the researcher and a University lecturer and forwarded to participants for accuracy. Students' Olympism education and conflict resolution integrated curriculum model unit evaluations were utilized to clarify information given in interviews. Data was analysed using thematic analysis with ethical issues highly considered throughout the study.

\section{Procedure}

This study has introduced an integrated model of Olympism values and conflict resolution strategies (here after called OE and CR, described below) and has been trialed in above mentioned six Sri Lankan state schools (A, B, C, D, E \& F) as a seven-months' intervention. A period of 40 minutes was allocated following their after-school basketball practice each week and during this period, students of the six schools (A, B, C, D, E \& F) received 
instructions on Olympism education and conflict resolution integrated curriculum lesson for a total of nineteen hours over 28 weeks. Physical education and basketball coaches in each school were given five days residential special training of Olympism and three teacher training workshops on Olympism and conflict resolution with the collaboration of the National Olympic Committee of Sri Lanka and the Ministry of Education (Western Province), Sri Lanka.

\section{The Olympism education and conflict resolution (OE \& CR) integrated curriculum model}

The model is designed to assist learners to understand and appreciate the importance of identifying the main characteristics of Olympism and how these could be used to learn conflict resolution under these ten different themes:

1. Introduction to Olympics (why Olympics?)

2. Historical development of Olympics (why they continue today and its association with conflict resolution)

3. Concepts of Olympism and conflict resolution strategies

4. Olympism and Tolerance; how it can be used for conflict resolution

5. Olympism and Fair play; how can it be used for conflict resolution

6. Olympism and Respect for others; how can it be used for conflict resolution

7. Olympism and Multiculturalism; how can it be used for conflict resolution

8. Olympism and Equality; how can it be used for conflict resolution

9. Olympism and Friendship; how can it be used for conflict resolution

10. Olympism and Non-discrimination; how can it be used for conflict resolution

The main intention for developing this curriculum model was to develop students' knowledge, attitudes and skills of positive conflict resolution strategies using Olympism education incorporated with sporting activities. These themes were divided into 28 sessions and each session was required to adhere to a special protocol.

Themes 1 and 2 included the historical development of the Olympic Games, Greek mythology, and Olympic Sanctuary and their association with peace. Theme 3 addressed the concepts of contemporary Olympism according to the Olympic charter (IOC, 2010) (Tolerance, Fair play, Respect for others, Multiculturalism, Equality, Friendship and Non-discrimination) and five strategies to manage conflict resolution (Smoothing, problem solving, Compromising, Withdrawing and Forcing) (Johnson \& Johnson, 2005). Identifying with the above concepts will provide students with information for 
the selection and planning of positive conflict resolution processes. Practical activities associated with themes 1, 2 and 3 included students' involvement in mini Olympic Games. Firstly, each student represents a different culture than his/her actual culture and was renamed using an appropriate name according to his/her new culture. Then, students were divided into play groups. From this grouping, students obtained the experience of playing in mixed cultures.

At this stage, students had taken this as an opportunity to plan a mini Olympic Games competition at their physical education lesson and these groups emulated actual IOC steering committees; such as athletic, finance, and cultural committees. Throughout the mini Olympic activities students developed their knowledge, skills and attitudes of the United Nations approved universal rights of participation in sport, acceptance of difference, respect for diversity, and UNESCO's theme of commitment in enhancing a culture of learning to live together. Additionally, the students were able to develop their 'critical literacy' on how to resolve problems which occurred while organising a competition. For instance, how to make plans for an event to fairly represent the diversity of participants without any discrimination, how to standardize fair judgement, and how to encourage equality among athletes were learned through these lessons. This is supported by Culpan and Wigmore's (2010) argument that to avoid the socio-cultural bias in society, it is important to challenge learners to develop a strong sense of social responsibility and social justice within and beyond the classroom through Olympism education.

Grupe (1996) emphasised three main goals of Olympic education: development of body, mind and character through a striving for achievement in physical endeavours and competition carried out always in the spirit of fair play, availability of a wide variety of sports and peace, friendliness, and international understanding. Therefore, the remaining themes 4 to 10 were structured with a strong combination of Olympism and conflict resolution concepts through sporting activities. These seven sessions consisted of conflict resolution exercises emphasising how to use Olympism values in different conflict situations while involved in physical activities and sport. Four steps of peacemakers (Johnson \& Johnson, 2005) were integrated with IOC Olympism concepts. Firstly, students learned that despite conflicts positive results may be achieved when conflicts are managed beneficially. Secondly, a six-step negotiation process (Johnson \& Johnson, 2005) was occupied to assist students to develop integrative agreements. These include:

1. Describing what you want

2. Describing how you feel

3. Describing the reasons for your wants and feelings 
4. Taking the other's perspective and summarizing your understanding of what the other person wants, how the other person feels, and the reasons underlying both

5. Inventing three optional plans to resolve the conflict that maximizes joint benefits

6. Choosing the wisest course of action to implement and formalize the agreement with a hand shake (p. 15)

During the above mentioned negotiation process, students learned how to use Olympism concepts that include fair play, tolerance, and multiculturalism with a view of conflict resolution in order to effectively control their anger, frustration and pressure. For instance, students learned to use tolerance when providing a description about what you want, and respecting others when describing how you feel. They also learned the consequences of cheating in sporting competitions by studying case studies of Olympic athletes that lost their reputation and prestige by cheating at world sporting events. Practical sporting activities associated with these integrated lessons were comprised with basic skills and 3 x 3 practice skills of basketball. Mixed cultural groups of students (previously mentioned) participated in above sports with enhanced critical thinking on why, how and when to tolerate while playing, how to play fairly, how to respect for multiculturalism while playing. This part of the model led students to develop their self-discipline and motivation for positive conflict resolution practice during sporting activity.

Students also had the opportunity to serve as mediators in conflicts by engaging in peer-mediated training lesson. At this intervention stage, peer mediation was also integrated with Olympism concepts of multiculturalism, non-discrimination, equality and friendship. Students exchanged their knowledge, skills and attitudes with fellow members of the all groups and discussed how they have worked well with conflict resolution, their identified weakness and ways in which improvements could be implemented.

\section{Findings and discussion}

The focus of this study was to examine the effectiveness of the Olympism education programme with the purpose of learning conflict resolution among ethnically segregated young students in Sri Lanka. An analysis of the participants' in-depth, focus group, semi-structured interviews revealed a number of findings that may promote young students' conflict resolution competencies through Olympism education. The key findings that emerged from this study were analyzed and reported according to the themes identified in the discussion below. 


\section{Olympism lessons improved students' conflict resolution competencies}

Interview results demonstrated significant gains in young students' ability to enhance their conflict resolution skills when they were exposed to Olympism education lessons through physical education, regardless of their ethnicity or gender. It was found that the $\mathrm{OE}$ and $\mathrm{CR}$ integrated curriculum model helped in the development of environments that respect individual differences and promoted students' emotional and physical well-being. When considering the students' narratives, one girl from School A indicated that critical thinking helped her when putting the OE and CR integrated model into practice.

We learnt about injustices in our community. Now I am more confident to think again and again what will happen if I encourage an injustice practice when we are playing.

According to School A boys, critical thinking which they have learned from the Olympism lessons has helped them to practice conflict resolution effectively. A boy from School-B commented:

Now I always think and re-think deeply what initiated to send a person out from our play team, what went wrong and who were accused as wrong when I deal with a conflict.

The finding that the comprehensive approach in Olympism education has enhanced their conflict resolution skills and their optimistic behaviour was also proved by students' evaluation reports. It was found that the perspectives of Olympism education that students attained by self-explorations through the practical activities of sport, deepened and broadened their knowledge and skills beyond what could have been achieved using textbooks alone. A girl from School A commented:

When you are in a team you think more as "we" rather than "I". We had to participate in many group activities in our programme, and we learned how to work in a team and how easy it is to communicate with each other.

Student interpretations revealed that they were competent enough to assess other people's opinions and adjust their behaviours by acclimatizing to confronted situations. This finding supports Hersh, Paolitto and Reimer's (1979) who state that "figuring out what is fair and learning how to cooperate and share are what interest elementary school youngsters, because they are developing the capacity to understand that other people see the world differently, as in cooperative problem solving" (p. 135). 
Combining Olympism values education with critical conflict resolution issues has been able to promote discussions around conflict resolution and has changed students' problem-solving situations. Correspondingly, a boy from School B commented:

I learned how to respect others and the importance of fair play while we are playing. It is a very good idea to think about others who play with us. They also like to win. So we must think about their happiness and try to play fairly.

Students were also more confident in managing their emotions in their present situations and in expressing their feelings of anger, frustration and indignity more intelligently. A boy from School B reflected that selfconfidence has helped him to control his emotions.

I used to get really angry at very little things. But, I learned from the lessons how not to react negatively all the time. I am glad that I don't get really angry as much as I used to.

It was noted that there was a decrease in negativity in attitudes towards injustice, inequality and assertiveness in students' conflict resolution practice. This is commensurate with previous findings in Greenburg's (1996, cited in Heydenberk, \& Heydenberk, 2005) study which suggests that conflict resolution programmes that provide students with opportunities for skill development in a cooperative context are related to significant increases in cognitive skills.

While above evidence supports the benefits of the intervention in promoting OE \& CR competencies of young students' conversely, the researcher found that some students experienced negative feelings about intervention lessons no matter what their gender or ethnic group was. Some of them were not energized by or enthusiastic in learning OE and CR lessons. Girls of Schools B, C and F stated:

Oh...I was exhausted

It is difficult to learn after playing Basketball as we are too tired

I should have brought something to eat as I was starving after practice

It seems that there was a widening gap in conflict resolution performance between normally vigilant and chronically tired pupils. Perhaps most persuasive cognitive fatigue of some students may have led to burnout at work. This is probably because we conducted these lessons soon after their college basketball practice and students may be were interrelated with 
tiredness and stress. This is supported by a finding of a research conducted by Marcora, Staiano and Monning (2009), emphasising that mental fatigue is a subjective feeling of tiredness and lack of energy and mental fatigue impairs physical performances of humans.

On the other hand, poor competencies of students can be affected by classroom factors such as teaching-learning environment, curriculum content and individual learning differences. Schools A and D boys stated:

Ifelt it was very difficult to understand what they were taught In our social studies class we learned these topics in a different way

This may be because students' ability to learn, their engagement in the intervention lessons may have been neutralized by their lack of enthusiasm in learning. And possibly, their academic competency levels may be a barrier to their classroom engagement. They may have shown low ability in their cognitive capacity. This is supported by Sperling et al, (2012) by revealing students with higher metacognitive ability are often more successful than those who lack the skill.

Academic achievements vary and learning does not affect every student in the same way. Classroom factors such as content difficulty may be associated with poor achievement. School E boy stated:

My friend is told that he could understand what our teacher was taught but I was fed-up with understanding

It seems contradictory that some students were struggling to understand what teacher was explaining. They were afraid and worried about not being able to understand what teachers were explaining. Perhaps most convincingly some teachers do not involve in best practice interactions of student learning and demotivated teaching-learning process may have affected students' conflict resolution skills. This is supported by Steele \& Cohn-Vargas (2013) emphasising students learn best when their teachers are responsive to their strengths and needs.

It was also revealed that negative conflict resolution were also experienced by some of the students. Boys of Schools C and F stated:

How can we tolerate their aggressive behaviour?

Why can't we kick them off instead? 
This may probably because negative attitudes of some students that are different and difficult to change may have negatively affect the educational experiences. There were different factors that triggered negative emotions factors such as home environment, peer-group motivations, and social interactions. Teachers cannot be expected to manage all the experiences effectively.

\section{Olympism lessons enhanced students' understanding of cultural differences}

A significant finding was that the use of the Olympic value of multiculturalism in this OE and CR integrated model helped students to think clearly and productively about the ethnic differences in their society, and substantially developed their citizenship competencies to promote effective conflict resolution skills and encourage social integration. Girls of schools B and C stated:

We play with so many youths with different ethnic backgrounds. We should always play with them together, thinking they are all like us.

We learned from these lessons that when living in this society we should treat all the people from diverse ethnic backgrounds the same.

School A and F boys revealed that positive feelings about cultural cohesiveness helped them to enhance their experience of living harmoniously.

There are so many talented youths in different ethnicities. We should learn to select them to our sports group as we need to have best performers.

We need to understand from an early age to treat and live with people from different ethnicities. Particularly, to respect their great talents at all then the team play would be highly valuable.

The comments from participant students have suggested that the Olympism values and conflict resolution integrated curriculum model of teaching has encouraged students to learn intercultural sharing of views and emotions, and helped them to find answers to community problems with a minimum of conflict.

Avruch (1998) emphasises that culture is a key factor in the evolution and resolution of conflicts. However, Day-Vines, Day-Hairston, Carruthers, 
Wall and Lupton-Smith (1996) point out that little attention has been focused on "integrating diversity" as a conflict resolution programme objective. Strengthening the argument, Deutsch (2003) suggests that the constructive use of conflict resolution skills is more likely if the social context is favourable to their use.

Parry (2003) emphasises that Olympism is a universal concept but the interpretation of the concept is culturally relative, since the ideas contained within Olympism generate their own meanings, language and practice. The study showed that the OE and CR integrated model facilitated the learning of multiculturalism in two ways. First, students of both schools (Singhalese and Tamil) dealt with aspects of multiculturalism, and they went on to explore effective ways of engaging in different multicultural contexts and dealing with problems and ways of living in a multicultural society. This is best described as "liberal / benevolent multiculturalism"; which, as May and Sleeter (2010) emphasise, has a focus on getting along better, primarily via a greater recognition of and respect for ethnic, cultural and or linguistic differences" ( $p$. 14). May and Sleeter (2010) further emphasise that "liberal multiculturalism abdicates any corresponding recognition of unequal and often untidy power relations that underpin inequality and limit cultural interaction" (p. 14). However, it should be noted that there is a degree of criticism of teaching about cultural differences, through liberal or benevolent multicultural educational approaches. They are likely to have at best only a mild and temporary effect (May \& Sleeter, 2010). Banks (2006) points out that both cultural knowledge and knowledge about why ethnic groups are victimised by institutional racism and class stratification need to be emphasised.

Secondly, to overcome the deficiencies noted above, the integrated OE and CR model helped students to consolidate and extend their previous learning and experience of "critical multiculturalism" (reflectivity of multiculturalism). Schools B, and E boys stated:

Sinhalese students don't let us come to the playground. Then we fight. We must change this situation. Why can't we just talk to them and solve our problem?

There are so many people using the common playground. We are thinking only Singhalese people don't allow us to come. Even our older students don't allow us to use the playground while they are playing. Why can't we talk together and arrange time to share the playground? 
Critical thinking on multiculturalism directed students to reflect about what went wrong and what went well in multicultural relationships, their previous experiences of unequal power relationship, racism and discrimination, and their learning and experiences about how to build solidarity across diverse communities. A girl of school A commented:

In our village, when Tamils came to the playground, we didn't like it. But now we've learned it's wrong and you can't think they shouldn't be allowed in the same playground, because they have nowhere else they can play.

Through this $\mathrm{OE}$ and $\mathrm{CR}$ programme, students were better able to appreciate cultural diversity and how to manage their lives in a multicultural setting. May and Sleeter (2010) emphasise that critical multiculturalism needs "both to recognise and to incorporate the differing cultural knowledge that children bring with them to school, while at the same time to address and contest the differential cultural capital attributed to them as a result of wider hegemonic power relations"(p. 14). During the OE and CR integrated intervention, students had the opportunity for meaningful examination of their own and others' cultural identities. This approach is supported by Lassoued (1997), who states that one of the main objectives of Olympism is teaching individuals to adapt to their living conditions.

Finally, the OE and CR integrated model activities also helped students to practice their new-found competencies to gain new insights and understanding of the United Nations-approved universal rights of participation in sport, acceptance of difference (pluralism) and respect for diversity, and UNESCO's theme of commitment to enhancing a culture of learning to live together. Girls in School B and F stated:

The best place for us children to mix with Singhalese, Tamil and Muslim children is the playground. Why do we want to mix with others? Because we can't live alone in this village.

We must respect others winning or losing. Can we win always? We can't always win. I learned how to appreciate other ethnic group's achievements.

These students' comments suggest that by providing a space to explore and practice critical issues of multiculturalism through the $\mathrm{OE}$ and CR integrated model, students were able to recognise that sport provides a safer space for cultural integration. According to DaCosta, Abreu and Miragaya (2006), Coubertin's multicultural approach was on the aspects between nation 
and culture and the beliefs of the period of 1908-1924. In view of this argument it seems that Coubertin's enticement of understanding specific cultural features of other nations to encompass unity. In this study it became clear to the researcher that the findings support Coubertin's comments that "Olympism is a destroyer of dividing walls" (Muller, 2000, p. 548). Therefore, it can be seen that Coubertin's idea of "building a peaceful and better world by educating youth through sport" can indeed apply to multicultural situations in contemporary societies like Sri Lanka.

\section{Conclusion}

To enhance conflict resolution competencies of young students at secondary schools, there is a strong case for a transformative education process which facilitates experience in various curriculum initiatives associated with sports. The primary purpose of this study was to examine the effectiveness of an Olympism education programme to enhance conflict resolution practice between Sinhalese, Tamil and Muslim secondary school students in Sri Lanka. This study demonstrated that education for cosmopolitan citizenship which develops competencies in conflict resolution can be achieved through Olympism education in association with sporting activities. A secondary purpose was to examine whether Coubertin's idea of "building a peaceful and better world by educating youth through sport" could indeed apply in contemporary societies. The lesson from this study is that sport on its own, while valuable in many ways, will not do a great deal towards conflict resolution skills and encouraging communal harmony. However, when combined with an educational programme, such as the one provided by the $\mathrm{OE}$ and CR integrated curriculum model which allows ample opportunity for reflection and practical skills application, it can be very valuable indeed in promoting positive values. Therefore, the study revealed that Coubertin's idea of "building a peaceful and better world by educating youth through sport" can be applied to multicultural situations in contemporary societies.

\section{References}

1. Alfermann \& Bussmann, (1988). In Patsantaras, N. (2008). Olympic Message: Olympic Ideology and Olympic social reality. Sport Management International Journal, 4(1), 45-54.

2. Andrecs, H. (2007). Aims, objectives and contents of Olympic pedagogy. $9^{\text {th }}$ International session for directors of National Olympic Academies. Olympia: International Olympic Academy.

3. Avruch, K. (1998). Culture and Conflict Resolution. Washington, DC: US Institute of Peace Publication.

4. Banks, J. A. (2006). Race, culture \& education: The selected works of James A. Banks. Oxon: Routledge. 
5. Bilgin, A. (2008). The impact of conflict resolution training on elementary school children. Elementary Education Online, (7), 541556.

6. Bodine, R., \& Crawford, D. (1996). Conflict resolution education: A guide to implementing programs in schools, youth-serving organizations, and community and juvenile justice settings program report. USA: U.S. Department of Education.

7. Boulding, K. (1963). Conflict and defense. New York: Harper \& Row Publishers.

8. Boulogne, Y.P. (1994). Humanism of Coubertinian neo-Olympism. In Y. P. Boulogne (Eds.). For a humanism of sport: After a century of Olympism, (pp. 11-29). Paris: IOC International Congress CNOSFEditions.

9. Brown, J.L., Roderick, T., Lantieri, L., \& Aber, J.L. (2004). The resolving conflict creatively program: A school-based social and emotional learning program. In J. E. Zins, R.P. Weissberg, M.C. Wang, \& H.J. Walberg (Eds.). "Building academic success on social and emotional learning: What does the research say? (pp. 151-169). New York: Teachers College Press.

10. Coubertin, P. (1936). In N. Muller (2000). (Eds.). Pierre de Coubertin (1863-1937) Olympism: Selected writings. Lausanne: International Olympic Committee

11. Culpan, I. \& Wigmore, S. (2010). The delivery of Olympism education within a physical education context drawing on critical pedagogy. International Journal of Sport and Health Science, (8), 67-76.

12. DaCosta, L., Abreu, N., \& Miragaya, A. (2006). Multuculturalism and universal proclaimed values in Olympic Movement: An approach to human rights and sport development. International Council of Sport Science and Physical Education Magazine, 2006. Retrieved on 3.6.2012.

From, http://www.sportsinbrazil.com.br/artigos_papers/multiculturalism.pdf

13. Day-Vines, N., Day-Hairston, B., Carruthers, W., Wall, J., \& LuptonSmith, H. (1996). Conflict resolution: The value of diversity in the recruitment, selection and training of peer mediators. School Counsellor, 43 (May), 392-410.

14. Deutsch, M. (2003) Cooperation and Conflict: A personal perspective on the history of social psychological study of conflict resolution. In Wiley \& Sons (Eds). International Handbook of Organizational Teamwork and Cooperative Working. (pp. 1-50). Hoboken, NJ: Chichester, West Sussex.

15. Grupe, O. (1997). Olympism is Not a System; it is a State of Mind. Olympic Review Feb/Mar, XXV, 63-65. 
16. Hersh, R., Paolitto, D., \& Reimer, J. (1979). Promoting moral growth: From Piaget to Kohlberg. New York: Longman Publishers.

17. Heydenberk, R., \& Heydenberk, W. (2005). Increasing meta-cognitive competence through conflict resolution. Education and Urban Society, $37(4), 431-452$.

18. International Olympic Committee. (2007). The Olympic Charter. Lausanne: International Olympic Committee.

19. International Olympic Committee. (2010). The Olympic Charter. Lausanne: International Olympic Committee.

20. Johnson, D. W., \& Johnson, R. (2005). Teaching students to be peacemakers. Edina, Minnesota: Interaction Book Company.

21. Kidd, B. (1996). Taking the rhetoric seriously: Proposals for Olympic Education. Quest, (48), 82-92.

22. Kruger, M. (2007). The evolution of Olympic pedagogy and its place in the modern education system. $9^{\text {th }}$ International Session for Directors of the National Olympic Academies. Lausanne: International Olympic Committee.

23. Lassoued, B. (1997). The Educational aspect of the Olympic ideal. Olympic Review. June/July 1997 XXVI.

24. Cardozo, M. L. (2009). Sri Lanka: In peace or in pieces? A Critical approach to Peace Education in Sri Lanka. Peace Education, Sri Lanka, Working paper 4. Retrieved on December 18, 2010, from http://www.educationanddevelopment.wordpress.com/publications.

25. Marcora, S. K., Staiano, W., \& Monning, V. (2009). Mental fatigue impairs physical performance of humans. Journal of Applied Physiology, 106(3), 857-864.

26. May, S., \& Sleeter, C. (2010). Critical multiculturalism: Theory and praxis. New York: Routledge Publishers.

27. Muller, N. (2000). (Eds.). Pierre de Coubertin (1863---1937) Olympism: Selected writings. Lausanne: International Olympic Committee Publication.

28. Muller, N. (2004). Olympic Education: University Lecturers on the Olympics. Centre d' Estudis Olympics, Universitat Autonoma de Barcelona (2004), 7. Retrieved on december 17, 2009, from http://www.olympicstudies.uab.es/lec/pdf/muller.pdf.

29. Naul, R. (2008). Olympic education. Oxford: Meyer \& Mayer Verlag Publishers.

30. Parry, J. (2003). Olympic education in practice. A paper prepared for the Centre d'Estudis Olimpics, Barcelona.

31. Ren, H. (1997). Culturalism and educational values of Olympism. Retrieved on June 15, $2009 . \quad$ From, 
http://www.66.102.1.104/scholar?hl=en\&lr=\&q=cache:TdciergD6coJ :www.ioa.org.gr/book.

32. Roberts, L., Yeomans, P., \& Ferro-Almaida, S. (2007). Project WIN evaluation shows decreased violence and improved conflict resolution skill for middle school students. Research in Middle Level Education Online, 30(8). Retrieved on February 22, 2010, from http://www.amle.org/Publications/RMLEOnline/Articles/Vol30No8/t abid/1406/Default.aspx.

33. Shields, D., \& Bredemeier, B. (1995).Character development and physical activity, (pp. 13-18). Champaign, Illinois: Human Kinetics.

34. Sperling, R. A., Richmond, P. S., Ramsay, M. \& Klapp, M. (2012). The measurement and predictive ability of metacognition in middle school learners. The Journal of Educational Research, 105 (1), 1-7.

35. Steele, D. M., \& Cohn-Vargas, B. (2013). Identify safe classrooms: places to belong and learn. London: Crowin press.

36. Stevahn, L., Johnson, D., Johnson, R., \& Schultz, R. (2002). Effects of conflict resolution training integrated into a high schools social studies curriculum. Journal of Social Psychology, 142(3), 35-51.

37. Thomas, K. W. (1976). Conflict and conflict management. In M. D.Dunnette (1976). (Eds.). Handbook of industrial organizational psychology, (pp. 889-935). Chicago: Rand McNally Publishers.

38. Vazsonyi, A. T., Belliston, C. M., \& Flannery, J. (2004). Evaluation of a school-based, universal violence prevention program: Low, medium and high risk children. Journal of Youth Violence and Juvenile Justice, (2), 185-206. 